\title{
Bentonite alteration revealed by a lab experiment and an in situ test, and its effect on the migration of uranyl in bentonite barrier studied by generic numerical models for high-level radioactive waste repositories
}

LIANGE ZHENG ${ }^{1}$, SHARON BORGLIN ${ }^{1}$, CHUN CHANG ${ }^{1}$, Chunwei ChOU ${ }^{1}$, YuXin Wu ${ }^{1}$, Jens BiRKHOLZER ${ }^{1}$,

${ }^{1}$ Lawrence Berkeley National Laboratory, 1 Cyclotron Rd Berkeley, CA, USA

The most common buffer material for engineered barrier system (EBS) is compacted bentonite, which features low permeability and high retardation of radionuclide transport. The alterations of bentonite over the course of being heated and hydrated may reduce the swelling capability and adsorption capacity and subsequently compromise some of the safety functions of EBS. One specific alteration is illitization, the transformation of smectite to illite. In this presentation, we first present the alteration of bentonite observed in a column test with MX- 80 bentonite being heated at $200{ }^{\circ} \mathrm{C}$ and hydrated granitic water, then we report the bentonite alteration that was revealed from data collected after the dismantling of the 18 -years in situ heating $\left(100{ }^{\circ} \mathrm{C}\right)$ and hydration experiment for bentonite. Lastly, numerical models for generic repositories were developed to study the alteration of bentonite in 100,000 years and its effect on the migration of uranyl when EBS interacts with different host rocks: clay rock and granite. Minerals precipitation in bentonite has been observed near the heater in the column test. In the in situ test, the dissolution of soluble minerals has been observed whereas the post-heating bentonite samples cannot be differentiated from the reference sample (prior to the test) in terms of the content of montmorillonite. The longterm numerical models show the occurrence of illitization in the bentonite for both clay rock and granite repository, which affects the migration of $\mathrm{U}(\mathrm{VI})$ through changing $\mathrm{pH}$ and the quantity of adsorbents. It is, however, the dissolution/precipitation of carbonate minerals exert a strong effect on the migration of $\mathrm{U}(\mathrm{VI})$ via regulating the aqueous complexation of U(VI) with carbonate and calcium. Different host rocks, i.e. clay rock vs granite leads to different interactions between EBS and host rocks and therefore different calcite dissolution patterns, which in turn affect the migration of $\mathrm{U}(\mathrm{VI})$ within the EBS. 